\title{
Los terrorismos a la tica. Casos y relatos que vinieron a mí
}

\section{Terrorism "a la tica" Some cases of the Environmental struggle Terrorismo costarriquenho. Casos e Histórias que me chegaram}

Mauricio Álvarez Mora

Geógrafo

Máster en Estudios Latinoamericanos

Recibido: 10/07/2018 Aceptado: 30/08/2018

\section{Resumen}

La violencia política, y el terrorismo de Estado, en particular, me encontraron hace varios años, por vivencias y testimonios que fui guardando. Estas vivencias y testimonios han hecho un mapa que, en tanto permanezca oculto, es de terror e impunidad. Descubrirlo y dibujarlo van de la mano, implica sacar la voz para hacerla palabra escrita, con más urgencia que estética, por el deber de un nunca más.

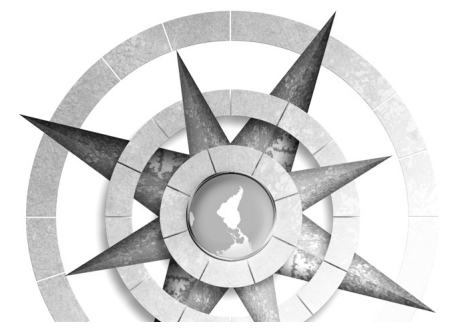

Si en otros lugares un campesino sin tierra invade una antigua finca de una trasnacional y en el desalojo la policía lo termina matando, se llama terrorismo de Estado o asesinato político; pero en Costa Rica hay un halo de paz y democracia que empaña lo que es claro, preciso y evidente.

Este no es un caso hipotético, ha sucedido al menos una decena de veces en Costa Rica.

Palabras clave: Lucha ambientalista, violencia política, conservacionismo, muertes de ambientalistas, Costa Rica.

\section{Abstract}

Political violence, and State terrorism in particular, found me several years ago, through experiences and testimonies that I have kept. These experiences and testimonies have drawn up a map that, as long as it remains hidden, is one of terror and impunity. To discover it and to draw it go hand in hand, and implies to raise the voice to make it a written word, with more urgency than aesthetics, by the duty of embracing a never again position. 
Keywords: Environmental struggle, political violence, conservationism, deaths of environmentalists, Costa Rica.

\section{Resumo}

Violência política e terrorismo de Estado em particular, me encontraram há vários anos, através de experiências e testemunhos que guardei. Essas experiências e testemunhos elaboraram um mapa que, enquanto permanece oculto, é de terror e impunidade. Descobri-lo e desenhá-lo é necessario, e implica levantar a voz para torná-lo uma palavra escrita, com mais urgência que estética, pelo dever de abraçar uma posição nunca mais.

Palavras chaves: Luta ambiental, violência política, conservacionismo, mortes de ambientalistas, Costa Rica.

La violencia política y el terrorismo de Estado, en particular, me encontraron hace varios años por vivencias y testimonios que fui guardando y han hecho un mapa que, en tanto permanezca oculto, es de terror e impunidad. Descubrirlo y dibujarlo van de la mano, sacar la voz para hacerla palabra escrita, con más urgencia que estética por el deber de un nunca más. Pero ya se preguntarán cómo llegué aquí. Voy a permitirme intimarles un poco. Hace algunos años, más de 25, empecé a militar en las filas del ecologismo, justo un año antes de ingresar a la Universidad de Costa Rica en 1992.
Al hacer un inventario de las opciones de participación política, tuve que hacer arqueología por paredes, baños, corredores y con los primeros cursos investigar el entorno. Un grafiti advertía que los baños de Ciencias Sociales eran los únicos espacios "liberados" para los compañeros gais, mientras otro mensaje los retaba: "lactantes fálicos, la u se privatiza y ustedes en estas". Empecé a entender lo que llaman la generación perdida, el reflujo de la izquierda, la fragmentación.

Un afiche de fondo rosado por la inclemencia de nuestro clima, con la efigie típica del Che, que parecía anunciar un funeral de la Juventud de Vanguardia Popular, me terminó de convencer de que era el ecologismo en lo que me sentía más auténtico. Además, ya tenía un año participando en la Asociación Ecologista Costarricense (AECO) que era un colectivo de jóvenes profesionales, poetas, biólogos y bohemios que venían construyendo espacios para jóvenes, comunidades urbano-marginales, rurales, indígenas y organizaciones populares y vecinales. Entre ellos, varios maestros fueron presentándome la historia de las revoluciones de Latinoamérica y todo un paradigma de lucha.

Uno de los testimonios más ínfimos, que todos deberían conocer, son las

68 Los terrorismos a la tica. Casos y relatos que vinieron a mí Mauricio Álvarez Mora 
torturas con cuerpos muertos, que por lo menos me confesó uno de "la familia”, torturado con el cuerpo de su propio hermano, abatido en el famoso y triste enfrentamiento donde también murieron policías.

En otro caso, el sindicalista Carlos Arguedas, en un desayuno junto al río Pacuare, a la altura de Siquirres, me confesó: "¿sabés por qué defiendo este río?", con los lagrimales activados, "este río me devolvió la humanidad y la esperanza”. Me contó cómo fue torturado por días y noches, durante la huelga bananera del sur, las noches que pasó durmiendo con un cadáver, "cuando salí de ahî", me dijo, no podía hablar, pasé meses sin poder comunicarme. De hecho, Carlos se internó en un playón del río Pacuare, pescaba y su mamá le dejaba comida sin lograr cambiar una palabra o un contacto con él. "El río me devolvió mi humanidad, no creía más en el ser humano, no tenía palabras, pero un día el río me curó”. Salió, y hasta el día de su muerte, Carlos fue un ejemplo, tanto al luchar y defender el ambiente, como al ser afectado por el nemagón, un cáncer fulminante que le apagó la luz, pero compartimos buenas luchas de las comunidades del Caribe y los trabajadores.

Con los años, seguía viniendo a mí el testimonio de prisioneros políticos como el de Livia Cordero Gené, quien estuvo cerca de dos años en prisión sin cargos o juicios, perdió su trabajo de docente universitaria y no contó con ayuda para reinsertarse en la universidad, como sí la tuvieron los exprisioneros de "la familia". Después, con los años, fui vecino de Livia, una mujer tan menuda como valiente, de sentencias y posiciones claras frente a la vida, fuimos compañeros del pintoresco comité patriótico contra el TLC de Barrio Escalante, entre las intimidades contaba cómo había sido arrestada en esa misma casa por militares gringos. ¡Sí, en Costa Rica, claro está! Esta casa se convirtió para el 2007 en uno de los sitios de reunión del comité. Unos años después vendió la casa, compró una finca en el Caribe y se dedicó a esperar la muerte por un cáncer que la fulminó en meses.

\section{Ecologistas muertos}

Parte de la historia de Livia la conocí por su sobrina María del Mar Cordero, quien muriera en un incendio en circunstancias que, contextualizadas, son un evento de terrorismo particular, pero consentido por el Estado. Ella murió una madruga fría de diciembre de 1994, cuando murieron otros dos compañeros ecologistas de la AECO en un incendio, nada accidental, pero que hasta el 
día de hoy tampoco ha sido reconocido como crimen.

No puedo explicar cómo de casualidad estuve ahí minutos después del incendio, como tampoco puedo discernir bien entre las imágenes en sepia de ese recuerdo que se confunde ya con otras escenas de horror y represión, como la masacre de la Embajada de España en Guatemala, donde murieron quemados decenas de compañeras y compañeros del Comité de Unidad Campesina en 1980. Años después, otro gran compañero, el profesor Alberto Moreno, me contó que revisando material audiovisual sobre el fuego me vio dando declaraciones a los medios de comunicación de aquel entonces. Trago duro, a mis veinte años oler carne quemada de los camaradas. Un policía me pasó la fatídica línea amarilla, pues aún no tenían datos de los ocupantes, y me tomó declaraciones y me invitó a verificar la casa que, aún humeante, no dejaba dudas de sus ocupantes.

Persisten impregnadas en mi memoria y en mis rincones la imagen y el olor de sus cuerpos pasando dentro de bolsas negras. Habitan la esquina arrugada de mi corazón, pero Óscar Fallas, Jaime Bustamante y María del Mar Cordero fueron seres con mucha luz y solidaridad, como todos los pueblos y realidades que vivieron y, gracias a esa luz, mi última imagen no es de desolación, es de alegría, es de sonrisas: una grande y abundante de María, otra que terminaba de achinar a Jaime y lo dejaba siempre joven y la bondadosa y honrosa de Óscar.

Los vientos alisios de diciembre traen recuerdos a los huesos, y la piel presiente que puede ser el pasado; sin embargo, los años han transcurrido y el dolor se ha transformado y la lucha ha seguido dando frutos que superan los intentos de represión y la desesperanza; ya creció una nueva generación de activistas ecologistas y muchas causas socioambientales se han ganado.

Si no hubo industrialización y destrucción del Golfo Dulce y expansión del odioso y devastador monocultivo de melina en Osa, tiene que ver directamente con el trabajo de aquellas tres sonrisas. Que hoy no exista minería o exploración petrolera ha sido un logro impulsado por su inspiración y por las bases que ellos crearon. Si hoy hay un gran protagonismo de comunidades en la acción ecologista, tiene que ver con su contribución con un modelo de trabajo que apostó por una alianza popular ecologista con una base amplia de participación comunitaria.

70 Los terrorismos a la tica. Casos y relatos que vinieron a mí Mauricio Álvarez Mora 
Unos ocho meses después de estos hechos, en el errático transitar entre vidas, aparece muerto otro compañero de la AECO, el joven poeta David Maradiaga. David murió el 14 de julio de 1995, pero no fue encontrado sino hasta el mes siguiente. Fue una muerte sumergida en sombras de anonimato y dudas, un asesinato hasta hoy impune. Su cuerpo fue recogido sin identificar en el parque Los Mangos, en Zapote, justo al frente de donde pocos años después tendría sus oficinas la Stone Forestal, transnacional que intentó industrializar el prístino Golfo Dulce con un monocultivo forestal llamado melina, ¿la ironía de la muerte?

A pesar de que familiares y compañeros visitamos hospitales, comisarías, incluso la morgue, fue por "casualidad" que un funcionario de la morgue lo identificó y, escribiendo su nombre, puso fin a la angustiante sensación del desaparecido.

Puedo decir que David es uno de esos personajes que cautivan pero asustan, como un gran remolino. Vivía como si supiese que no podía darse el lujo de dormir, sabiéndose con tiempo limitado entre las carnes corpóreas, un tobogán del que se recuerda el inicio pero que se difumina en mil partes al final de la madrugada o de los días siguientes de trasnoche.
Los ecologistas no mueren, los poetas tampoco. Cada vez que escucho poesía no tengo más referencia que su voz y agudas hipérboles cruzadas por galácticas metáforas y ácidas denuncias del momento que le tocó vivir. Para mí la poesía tiene su voz.

La fuerza de su palabra denunciando el asesinato de Chico Méndez, como si fuera su autoepitafio, no deja de estremecer. Pocas personas he conocido con su sensibilidad. Un candidato a permanecer en lo profundo de la conciencia y en un rincón del lado izquierdo del corazón. "Antes que ecologista soy humanista”, decía David.

Los recuerdos de aquellos días de agosto 21 años atrás, ya borrosos en sepia, los atesoro como momentos de mucha amargura y liberación. Porque imagino que la muerte debe de ser un tránsito para liberarse de la preocupación de vivir, pero si a uno "lo mueren", y apenas de 27 años, debe de ser distinto. ¿Quedará confundido? ¿Quedará errante? ¿Naufraga el alma en el infinito trasnochar?

Estos cuatro camaradas de la AECO son parte de al menos diez asesinatos políticos a ecologistas que se perpetraron entre 1975 y 2014, la mayoría continúa en la impunidad. 
El más antiguo que encontré registrado fue el de Olof Wessberg (1975), conservacionista que después de una larga lucha de más de 20 años creó la Reserva Cabo Blanco, fue asesinado en una visita a Corcovado, explorando la idea de convertirlo en parque nacional. El joven que había servido como guía había sido quien lo asesinó. Según una de las hipótesis fue "en beneficio" de los habitantes de Corcovado, que no querían que su tierra se convirtiera en un parque nacional. El acusado fue juzgado, sentenciado y enviado a prisión (Tjäder, 2014).

Otro dirigente, Óscar Quirós (1992) muere a balazos dentro de su casa, en un tipo de ajusticiamiento ambiental, se cree que este dirigente de la lucha en contra de la deforestación en Sarapiquí fue muerto por madereros, debido a sus constantes denuncias. Óscar, además, era el presidente de la Asociación de Desarrollo Comunal de Cubujuquí y su asesinato quedó en la impunidad, pues nunca se determinó un culpable por vía judicial (Delgado, 2015).

La ambientalista canadiense Kimberly Blackwell fue asesinada a finales del 2011 en la Península de Osa, justamente en esta exuberante región, donde afloran todas las contradicciones socioecológicas de nuestro país. La chocolatera -como se conocía a Kimberly por la fabricación de chocolate casero- tuvo varios enfrentamientos con cazadores ilegales y se presume que por venganza la mataron. Inclusive, un cazador de la localidad estuvo en prisión preventiva como sospechoso de su asesinato. Pese a la presión de la familia, quienes contrataron a un investigador privado, de la embajada y hasta del primer Ministro canadiense, hoy desconozco si hubo condena por este caso (Boddiger, 2011).

Un caso parecido al de Kimberly fue el de Jorge Aguilar (1992), que luchaba contra la cacería ilegal. Salió a patrullar en Cartago y no volvió a su casa. Los familiares encontraron su cuerpo en una zanja. El último caso documentado en nuestro país fue el de Diego Armando Saborío, que según la prensa nacional habría sido asesinado "por defender a los animales silvestres de una finca propiedad de su familia, en Chamorro de Cutris en San Carlos" (Hernández, 2014).

Sobre el caso más sonado, de Jairo Mora (2013), como muchas personas más, así lo conocí: el día que fue asesinado. Nunca nos cruzamos en el camino, pero en estos tres años ha sido mi amigo, un joven cuya suerte pudo haber sido la de cualquier otro defensor de la Tierra.

72 Los terrorismos a la tica. Casos y relatos que vinieron a mí Mauricio Álvarez Mora 
Hoy lo veo en obras de teatro, lo llevo en una camiseta, está en mi refrigeradora en una calcomanía, mi hija igual que otras tantas personas lo quieren, porque Jairo se abrió un campito en nuestros corazones.

Este año en un aniversario de ALCOA, en abril, conocí a su madre y sus hermanas, nos encontramos en un homenaje para él y otros ecologistas a quienes se les arrebató la vida en nuestro país y en el mundo. En el acto, organizado por la FEUCR, se inauguró el "Jardín conmemorativo de ecologistas: una semilla desde ALCOA". Allí, la madre de Jairo leyó una carta escrita por él cuando era niño. Parecía fiel presagio de su noble misión en la vida: amar al mar y la vida como amó a Gandoca y las tortugas. El texto era casi una disculpa anticipada a su madre, como si supiera que sería asesinado desde mucho tiempo atrás.

En aquel homenaje también descubrí, por medio del testimonio de Gino Biamonte, ecologista y profesor universitario, a otro personaje olvidado, que el mismo Jairo vino a empujar a estas letras. Su nombre no lo hemos podido ubicar, pero por ahora lo nombramos y lo invocamos como "Pecho de mula", el vecino de Horquetas de Sarapiquí que, junto con la organización APREFLOFAS, denunció una tala ilegal, allá por el año 1985, dentro del Parque Nacional Braulio Carrillo. Un maderero lo habría mandado a matar. En su propia casa, con su hijo en brazos, murió de un balazo en la cabeza. ¿Qué pasó en el sistema judicial? ¿Por qué no hay nombre? ¿Qué fue de su familia? Este caso puede ser evidencia del desconocimiento de más casos que, como el suyo, además de impunes, están en las tinieblas. Estamos buscando su nombre para así completar su historia.

\section{Lucha por la tierra}

No es coincidencia que los actores sociales más afectados por estas formas de terrorismo sean ecologistas, campesinos e indígenas. El problema es estructural: conflictos por tierras: por tenerla o defenderla, y conflictos ambientales, han sido parte de un círculo de violencia que nos aleja de cualquier mito de paz y respeto a los Derechos Humanos en Costa Rica.

Meses atrás, me preguntaba un periodista del Semanario Universidad si el sector más afectado por asesinatos era el ecologista. Dudé en afirmarlo, pues tengo muy presente que la justa lucha campesina por la tenencia de la tierra ha sido motivo de persecución y asesinato de muchos campesinos (Chacón, 2016). 
Me di a la tarea de buscar nombres que, así como "Pecho de mula", fueron surgiendo de libros, pero sobre todo de las comunidades, de testimonios y de distintas experiencias de la vida. Durante varias semanas pregunté y pregunté. Un dato me llevó a otro. Era como si uno me "jalara" a otro, igual sé que no logré completar todos los nombres. Es un mapa de la memoria histórica que hay que construir de manera colectiva y más sistemática. Sin embargo, la lista es un punto de partida potente, verlos juntos y nombrarlos uno a uno, con dignidad, aporta al camino, tal y como quedó documentado en un artículo periodístico que se suma a este sendero (Chacón, 2016).

Cuando empecé la lista, el primero que vino a mi memoria fue Gil Tablada, oriundo de La Cruz, Guanacaste, asesinado el 18 de noviembre de 1970 de dos balazos por el latifundista Luis Morice Lara, quien se oponía a la presencia de campesinos en esas tierras. Supe de la existencia de este caso porque en la AECO se colaboraba con la comunidad que hoy lleva el nombre de Gil Tablada, aunque hay quienes la siguen denominando como se llama la finca del señor Morice: "El Jobo". Mientras la historia poco conocida fue presagiada por Carlos Luis Fallas, "Calufa", años antes, en un ensayo, "Don
Bárbaro", pues habla de los abusos e injusticias cometidos por los grandes latifundistas cruceños, e inclusive, ya mencionó al futuro asesino Morice (Vargas, 2010).

En 1981, una década después en la misma zona, la Guardia Rural, con terrorismo, desalojó violentamente a campesinos que ocupaban tierras en Paso Bolaños. La policía disparó y Pedro Lara fue asesinado. Un año más tarde, una huelga en Sixaola terminó con varios campesinos asesinados. En otra huelga en el año 2000, casi dos décadas después, Carlos Fletes, campesino y trabajador bananero, terminó asesinado por la policía también en Sixaola. Recuerdo la expresión y las lágrimas de su familia y vecinos cuando llegamos con un afiche en medio aún de la huelga, con su cara en grande, exigiendo justicia.

Otro de los hechos que marcó mi vida fue la militarización de San Vito de Coto Brus. Era tan solo un niño en 1984, cuando los campesinos y las campesinas tomaron una finca en las Alturas de Cotón y, como respuesta represiva, en el desalojo hecho por el gobierno fue asesinado el campesino Antonio Prendas. Los testimonios señalan al abogado Roig Mora como presunto responsable del crimen. Recuerdo que eran tantos los

74 Los terrorismos a la tica. Casos y relatos que vinieron a mí Mauricio Álvarez Mora

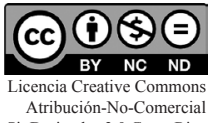


campesinos arrestados, que la policía usó el redondel de toros del pueblo como cárcel.

Quizás habían aprendido la fórmula desde la utilización del Estadio Nacional en Chile en los años de la dictadura pinochetista. Recuerdo que llevaba cobijas, víveres o mensajes a la gente recluida, era muy niño, pero consciente de que aquella era una lucha justa.

De la voz del también asesinado Óscar Fallas, escuché hablar de las violentas luchas por la tierra en Pavones, que acabaron con la vida de Álvaro Aguilar (1996) en un enfrentamiento con los narcoparamilitares, que dejo más de 20 agricultores heridos por arma de fuego (Méndez, 2016). En 1991 fue asesinado el campesino Víctor Hugo Vargas Villalobos, por un conocido narcoterrateniente: Daniel J. Fowlie. En Drake de Osa, en el asentamiento Tesoro Verde, los terratenientes apellidados Aguilar asesinaron a un campesino llamado "Rafa" (Cordero, 2011, p. 63).

En el 2001, mataron al campesino Randall Muñoz, tras un desalojo ejecutado en Bambuzal de Sarapiquí; en el 2013, fue asesinado Gerardo Moya. Estos dos, muertos con armas de reglamento policial en un conflicto por tierras con la Standard Fruit Company (Vizcaíno y Segnini, 2003).

Hay registros orales y testimoniales que no logré corroborar con otras fuentes, como el asesinato de un campesino en el asentamiento $\mathrm{Ne}$ guev, en Parismina de Guácimo, no recuerdo el nombre, pero sí la historia de represión, en la misma lógica de tierra arrasada, y cómo eran cercados en la montaña los campesinos y baleados por la fuerza pública que defendía a un terrateniente local.

En la Propuesta a la Concertación en 1998, el Frente Agrario de Organizaciones Sociales, cuando se refiere a los conflictos agrarios reivindica como mártires del sector a: Celso Garita, asesinado en la hacienda Chapernal por paramilitares en marzo de 1994; Álvaro Monge Jiménez, asesinado el domingo 26 de noviembre de 1995 por una banda paramilitar en Los Ángeles, Río Jiménez de Limón; Miguel Trejos Sandoval, asesinado el sábado 30 de diciembre de 1995 por una banda paramilitar en los Cenízaros, 26 millas de Batán de Limón; y Porfirio Céspedes, indígena cabécar asesinado en 1985.

Durante el periodo de la guerra contrainsurgente en Nicaragua, se denunció el asesinato del dirigente

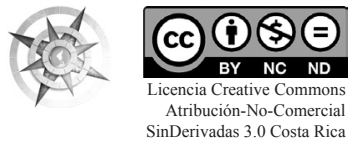


"campesino Antonio Mendoza, en la zona norte cuando la CONTRA nicaragüense, se paseaba como "Juan por su casa", durante la administración Monge Álvarez" (Contreras, 2002). Además, debe recordarse todo el entrenamiento contrainsurgente recibido por miles de policías costarricenses en la Base Militar del Murciélago, por parte de asesores militares gringos (Reuters, 1985).

\section{Pueblos indígenas}

En Costa Rica, las formas de violencia organizada tipo paramilitar ya se han hecho presentes en reiteradas ocasiones, en territorios indígenas como Salitre, Cabagra y Térraba, y están latentes en otros territorios, también indígenas, pero donde predominan los "blancos" que no les ha bastado con todo lo usurpado, sino que siguen robándoles a quienes son poseedores legales y legítimos de esos territorios indígenas.

El luchador indígena Antonio Zúñiga fue asesinado en circunstancias no establecidas y, por lo tanto, impunes, en el territorio indígena de Ujarrás (1990). Antonio se caracterizaba por defender los bienes de su pueblo, enfrentándose más de una vez a los cazadores ilegales... los famosos "monteadores" no indígenas. Y fue precisamente así como perdió su vida. Recientemente, la UNED realizó un homenaje en la comunidad, y los hijos de Antonio señalan al asesino de su padre como blanco que usurpa tierras indígenas, en un contexto de mucha violencia en los territorios indígenas del sur.

Otros antecedentes se relacionan con el grupo policíaco paramilitar "Comando Cobra", que fue parte de la Guardia de Asistencia Rural (GAR) entrenado para supuestamente erradicar la marihuana de Talamanca, y que terminó sembrando el terror en la zona. Sus integrantes fueron condenados por el asesinato de dos indígenas y la violación de al menos dos mujeres indígenas, así como por hurtos y privaciones agravadas de libertad (Aguilar, 1996). En la misma zona, otro grupo paramilitar de extranjeros, supuestamente misioneros, fue denunciado recientemente por indígenas ( $\mathrm{La}$ Prensa Libre, 2013).

Pero la historia de agresión, persecución y racismo contra nuestros pueblos indígenas se remonta a la época de la invasión de los europeos, y se recrudece con la esclavitud, que hasta hace relativamente poco -finales del siglo XIX- era legal. Se vendían en Costa Rica esclavos negros o chinos a 200 o 300 pesos según fueran de primera y segunda clase.

76 Los terrorismos a la tica. Casos y relatos que vinieron a mí Mauricio Álvarez Mora 
Pero la memoria en Costa Rica es flaca, corta y manipulable. Nuestra condición indígena y nuestra diversidad han sido profundamente negadas, al punto de que estas indignantes palabras fueron dichas por el entonces Presidente de la República Rafael Ángel Calderón Fournier, que en la II Cumbre Iberoamericana en España, durante una entrevista y en respuesta a una interrogante sobre la conmemoración de los 500 años de la invasión europea, todavía llamada "descubrimiento de América", comentó: "En nuestro país no hubo derramamiento de sangre, ni enfrentamiento con España. Curiosamente, en Costa Rica no había población aborigen. Este país se forma de inmigrantes que empiezan a llegar hace poco menos que quinientos años. Humildes campesinos españoles que vinieron a trabajar y a forjar una nación de paz" (Urquisa, 1992).

Lo cierto es que en Costa Rica hay ocho pueblos indígenas vivos o más bien sobrevivientes a la aniquilación sistemática de personas originarias y de su cultura, sobrevivientes de un genocidio sentado sobre las bases del racismo y el eurocentrismo. Así es como, en el 2016, unos no tan humildes y pacíficos "no indígenas" se han dedicado a usurpar, linchar, machetear y marcar indígenas como ganado. Son "blancos ganaderos" que gobiernan a su antojo, de facto, incluso se podría afirmar que tienen más presencia que la misma institucionalidad del Estado.

Estos grupos actúan al margen de la ley, al mejor estilo paramilitar, como quedó en evidencia tras distintos hechos y acciones directas en Buenos Aires de Puntarenas, donde ya han echado mano de dinamita, machetes, bombas molotov y otras muestras de violencia, como linchamientos, ataques premeditados con armamento pesado y tanques de gas dispuestos a detonarse debajo de los puentes.

Todo esto ligado a que los pueblos indígenas están inmersos en un narcocontexto que no es un secreto: la siembra y el trasiego de drogas en los territorios indígenas es cada vez mayor, y estas actividades son realizadas en su mayoría por no indígenas.

Se arrastra una falta de legitimidad histórica y política, en relación con los pueblos indígenas, que cruza todos los vínculos de estos pueblos con el Estado y sociedad. Son relaciones marcadas históricamente por el despojo, el desprecio y el racismo. Nacen, crecen y se reproducen en un contexto de sometimiento, constante reducción de territorio y relaciones de poder desiguales, producto

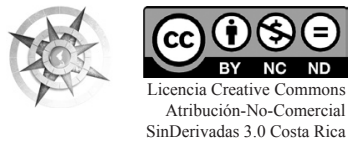


del colonialismo que permanece vivo desde hace siglos bajo el avasallamiento permanente que ha incluido el genocidio.

\section{Terrorismo a la "tica"}

Pocos o muchos, indígenas, campesinos o ecologistas. Diferentes o no, juzgue usted. Lo cierto es que en la defensa de la Tierra la sangre termina abonando sueños y utopías que nacen, crecen y se reproducen como cualquier cultivo, dan frutos y mueren para continuar la vida.

En este pequeño país, el Estado ha cometido "terrorismo" una y otra vez. Sembrar el miedo y usar la represión por medio de la fuerza han desembocado en el asesinato de personas. Esta realidad clara y concreta no tiene nada que ver con la imagen idílica de las postales turísticas. Decirlo no es cómodo, es incluso peligroso.

Ahora bien, si pareciera extremista decirlo de esa manera, "maticémoslo" diciendo que es terrorismo de Estado "a la tica", que no fue o es tan sistemático ni masivo como el de las realidades vecinas. Lo cierto es que hemos tenido igual número de pseudomilitares o policías entrenados en la Escuela de las Américas, ahora Fort Benning, que "aquellos violentos países vecinos".
En Costa Rica, tenemos fuerzas policiales que están armadas y entrenadas para hacer terrorismo "civilizado". Policías militaroides que han ejecutado las órdenes que parecen convertirse en un tipo de guerra de baja intensidad. Estos hechos, que quisiéramos creer que son actos aislados, como los asesinatos, la represión, la provocación del miedo y la criminalización de la protesta, se acercan más a una lógica o política de Estado.

Estamos hablando del mismo cuerpo policial que fue denunciado por estar envuelto con el asesoramiento de las bandas paramilitares para disparar y reprimir a campesinos en Medio Queso, durante el conflicto agrario, donde más bien los campesinos están acusados por invasión y resistencia a la autoridad, pero se ignora si hubo algún proceso disciplinario para sancionar, trasladar o promover al encargado de la Fuerza Pública de Los Chiles, quien fue grabado dando consejos de cómo matar campesinos eficientemente (Elpais.cr, 2012).

Entre los antecedentes, no podría dejar de mencionar las "fosas de la tortura" en los sótanos del OIJ, donde muchos militantes y ciudadanos recibieron torturas y aislamiento, denunciadas a principios de 1980 (Dobles, 1997). Tampoco sobra el dato del asesinato y tortura, por

78 Los terrorismos a la tica. Casos y relatos que vinieron a mí Mauricio Álvarez Mora 
agentes del Organismo de Investigación Judicial, del menor de edad William Malcolm Lee, detenido por presuntamente liderar una de las bandas denominados los "Chapulines". En este hecho, se dio un comportamiento similar al de cualquier escuadrón de la muerte, donde el detenido muere en tortura y su cuerpo es lanzado a un precipicio de la carretera del Cerro Zurquí.

Todos estos hechos son parte del terrorismo. Puede ser muy duro y triste reconocerlo, pero más grave sería no hacerlo. Mirar para otro lado. Y no tenemos que irnos a las luchas campesinas, indígenas o ecologistas para encontrarnos con el terrorismo. ¿Es que acaso no podemos afirmar que durante el referéndum del TLC sufrimos una campaña de terrorismo, con un Estado que usó métodos ilegítimos, como fue evidenciado por el memorándum del miedo, que incluyó además intervencionismo de la embajada de EE. UU.? ¿Acaso no fuimos coaccionados para decir sí en un referéndum totalmente antidemocrático?

El modelo de desarrollo actual genera, automáticamente, intolerancia hacia los que defienden la vida y los bienes públicos de la apropiación transnacional y privada. Esta intolerancia se está materializando en un discurso, repetido por la prensa comercial, que busca descalificar y desprestigiar a un movimiento ambiental cada vez más necesario, legítimo y amplio. Se repite la imagen del ecologista como una persona violenta, radical, que se dedica a oponerse a todo, creando una generalización que busca que la gente sea insensible a los hechos de violencia y hasta los llegue a justificar.

Es un círculo de violencia, lo he venido viendo a partir de mis decisiones y de la cercanía con algunas víctimas de estos terrorismos. He documentado y llevado estadísticas, he encontrado más de 75 tipos de agresiones contra defensores del ambiente en las últimas décadas, que incluyen 18 casos de demandas individuales y 7 de demandas colectivas, más de 36 activistas judicializados, 20 atentados o ataques directos, 10 incendios a casas o locales, 20 casos de amenazas de muerte.

Cuando un policía dispara a la celda donde estaba Viviana Gallardo, su última decisión o instinto de vida fue proteger con su cuerpo a Alejandra Bonilla Leiva que en ese momento estaba embarazada. Las personas participantes de "la familia" tardaron más de 30 años en romper su pacto de silencio implícito y explícito. En el caso de Alejandra, le tomó 35 años y en una entrevista en Telesur, donde describe a Gallardo como sensible y 
comprometida con el momento que le tocó vivir, hace la siguiente reflexión: "Es un asesinato desde el Estado, no es un asesinato en la calle o de un cuerpo paramilitar, es en un establecimiento del Estado, directamente por la policía".

La valoración que hace es que se quiere intimidar a la juventud en ese momento y no solamente perpetrar el asesinato: "esto les puede pasar si se organizan y luchan". A cualquiera que quiera tocar el sistema. La represión con estas características cumple ese papel demostrativo. Con participación de diferentes instancias del Estado, sin mayor investigación, cubierta bajo esta nebulosa construcción de que "aquí no pasa nada", marcada por la impunidad. Construir un monstruo de Viviana para justificar su asesinato, en impunidad de los autores intelectuales, alienta un silencio y un temor colectivos, que impiden hablar de estos hechos por décadas. Precisamente, para crear terrorismo estatal y civilizado.

Hay que dejar escapar las palabras, que se hagan letras y se impriman para contar estas historias, porque de ellas retoñará de a poco la justicia. Ya no solo para ellas y ellos, presentes en este ensayo, sino para otros y otras que desconocemos, cuyas historias deben ser contadas como primer paso para buscar algún tipo de justicia, para decir "nunca más" y recuperar así la dignidad de este territorio.

\section{Referencias}

Aguilar, R. (1996). "Testigos hundieron a Mínor Masís". En La Nación, 125-96. Consultado en: http://wvw. nacion.com/ln_ee/1996/mayo/12/ pagina16.html

Boddiger, David (2011). "Reward offered in Canadian woman's murder in Costa Rica" 6-2-2011. Consultado en: http://www.ticotimes. net/2011/02/06/reward-offered-incanadian-woman-s-murder-in-costarica

Chacón, Vinicio (2016). “¿Por qué se asesinan ambientalistas en Costa Rica?". En Semanario Universidad, 3-2-16. Consultado en: http://semanariouniversidad.ucr.cr/pais/por-que-se-asesinan-ambientalistas-en-costa-rica/

Chacón, Vinicio (2016). "Modelo productivo incide en conflictos agrarios". En Semanario Universidad, 8-3-16. Consultado en: http://semanariouniversidad.ucr.cr/pais/modelo-productivo-incide-conflictos-agrarios/

Contreras, Gerardo (2002). "Por decir la verdad". En Semanario Universidad, 24 5-2002. Consultado en: http://www. semanario.ucr.ac.cr/edicionesantiguas/ ediciones2002/M5Mayo_2002/1480_ MAY24/pais3.html

Cordero, Allen (2011). "Los Movimientos Campesinos Costarricenses vistos a través de tres casos de asentamientos del IDA". Cuaderno de Ciencias Sociales. Facultad Latinoamericana de

80 Los terrorismos a la tica. Casos y relatos que vinieron a mí Mauricio Álvarez Mora

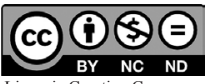

Licencia Creative Commons Atribución-No-Comercia SinDerivadas 3.0 Costa Rica

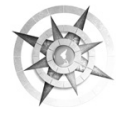


Ciencias Sociales (FLACSO). Consultado en: http://unpan1.un.org/ intradoc/groups/public/documents/ icap/unpan050060.pdf

Delgado, David (2015). "9 muertes de ambientalistas permanecen sin castigo". En La Nación, 2-2-2015. Consultado en: http://www.nacion.com/sucesos/crimenes-asaltos/crimenes-ambientalistas-permanecen-culpables_0_1467253299.html

Dobles, Ignacio (1997). "Derechos humanos y autoritarismo en Costa Rica". En Reflexiones, Vol. 57, № 1, Consultado en: http://revistas.ucr. ac.cr/index.php/reflexiones/article/ download/10963/10344

Elpais.cr (2012). "Audio descubre planes policiales para matar campesinos en norte de Costa Rica". 24-11-2012. Consultado en: http://www.radiolaprimerisima. com/noticias/131610/audio-descubre-planes-policiales-para-matar-campesinos-en-norte-de-costa-rica-

Frente Agrario de Organizaciones Sociales (1998). Propuesta a la Concertación. Consultada en: www.mideplan.go.cr/concertacion/...rural/desarrollo-rural-faos1.doc

Hernández, Carlos (2014). "Universitario asesinado por proteger animales silvestres". En La Nación, 14-10-14. Consultado en: http://www.nacion. $\mathrm{com} /$ sucesos/crimenes-asaltos/Universitario-asesinado-proteger-animales-silvestres_0_1445055500.html

La Prensa Libre (2013). "Paramilitares invadieron Talamanca como misioneros". 18-7-2013. Consultado en: http://test.prensalibre.cr/ nacional/86693-paramilitares-invadieron-talamanca-como-misioneros.html

Méndez, Alexánder (2016). "La gente no puede entrar como al patio de su casa". En Diario Extra, 26-1-2016. Consultado en: http://www.diarioextra.com/Noticia/detalle/282205/la-gente-no-puede-entrar-como-al-patio-de-su-casa

Reuters (1985). "Estados Unidos enviará asesores militares a Costa Rica para formar una unidad de elite". En El País, 7-5-85. Consultado en: http:// elpais.com/diario/1985/05/07/internacional/484264823_850215.html

Tjäder, Agneta (2014). Olof Wessberg y Karen Mogensen: Gestores de la Creación de la Reserva Natural Absoluta Cabo Blanco. Consultado en: http://investiga.uned.ac.cr/revistas/index.php/biocenosis/article/ download/807/684

Urquisa, Alonso (1992). "Entrevista con Rafael Ángel Caderón Fournier, Presidente de Costa Rica”, en ABC de España, pg. 41. Consultado en: http://hemeroteca.abc.es/nav/Navigate.exe/hemeroteca/madrid/ abc/1992/07/23/041.html

Vargas, Rónald (2010). "Gil Tablada Vive: 40 Aniversario del Martirio del Líder Campesino, en La Cruz, Frontera Norte". Consultado en: www.amerindiaenlared.org/download/1370/ gil-tablada-vive

Vizcaíno, Irene y Segnini, Giannina (2003). "Toma de finca en Bambuzal, Horquetas de Sarapiquî". En La Nación, 21-7-2003. Consultado en: http:// wvw.nacion.com/ln_ee/2003/julio/21/pais1.html \#2044906 